\title{
FIRST- DERIVATIVE SPECTROFLUORIMETRIC DETERMINATION OF ENROFLOXACIN AND CIPROFLOXACIN IN COW MILK USING ROTATING SORPTIVE EXTRACTION
}

\author{
M. GABRIELA ARRIAGADA ${ }^{a^{*}}$, DIEGO PINO ${ }^{a}$, PABLO RICHTER $^{b}$ AND M. INÉS TORAL ${ }^{a}$ \\ ${ }^{a}$ Departamento de Química, Facultad de Ciencias, Universidad de Chile, casilla 653, Santiago. \\ ${ }^{b}$ Departamento de Química Inorgánica y Analitica, Facultad de Ciencias Químicas y Farmacéuticas, Universidad de Chile, casilla 233, Santiago, Chile.
}

\begin{abstract}
A derivative spectrofluorimetric method for simultaneous determination of enrofloxacin (EFX) and ciprofloxacin (CFX) in cow milk was developed. The sample preparation was based on rotating disk sorptive extraction (RDSE) using Oasis HLB® as extraction phase and followed by desorption of the analytes with methanol. The final extracts were evaluated by derivative spectrofluorimetry.

An analyte-free cow milk was used as blank sample which was spiked with a known amount of analytes for the study of variables. The sample was treated with trichloroacetic acid in order to precipitate proteins. Furthermore, the extraction was carried out in the presence of Mc Ilvaine-EDTA 0.3M buffer to avoid any type of interference from the calcium ion. The variables involved in the RDSE process were $\mathrm{pH}$ and extraction time.

Spectral variables were also optimized and analytical signals were evaluated at $417 \mathrm{~nm}$ and $438 \mathrm{~nm}$ for EFX and CFX, respectively.

The limit of detection (LOD) and limit of quantification (LOQ) were $2.98-9.04 \mu \mathrm{g} \cdot \mathrm{L}^{-1}$ and $2.56-7.75 \mu \mathrm{g} \cdot \mathrm{L}^{-1}$, for EFX and CFX respectively. The precision levels, expressed as relative standard deviation, for EFX and CFX were 3.2\% and 3.0\%, respectively. The recoveries were between $98.8 \%$ to $100.5 \%$.

Commercial milks were analyzed and both antibiotics shown concentrations below to LOD in the batches analyzed. Finally, the proposed method offers advantages in terms of simplicity, efficiency and cost. Besides being friendly with the environment.
\end{abstract}

Keywords: Ciprofloxacin, Enrofloxacin, Derivative spectrofluorimetry, cow milk.

\section{INTRODUCTION}

Enrofloxacin (EFX) and its metabolite ciprofloxacin (CFX) are a secondgeneration of quinolone antibiotics, fluoroquinolones ${ }^{1}$. Fluoroquinolones possesses a fluorine atom at the C-6 position and a piperazinyl group at the C-7 position. The addition of both groups improves the antibacterial activity of quinolones against gram-positive and gram-negative pathogens. The antimicrobial activity of quinolones against Haemophilus paragallinarum, Pasteurella spp, E. coli, Salmonella spp, Mycoplasma spp, Staphylococcus spp, and Erysipelothrix rhusiopathiae acts in the selective inhibition of the DNA gyrase enzyme, which is necessary for the synthesis of bacterial DNA ${ }^{2}$. Fluoroquinolones are used to treat a variety of infections in humans, such as urinary, respiratory, gastrointestinal, and sexually transmitted infections ${ }^{3 .}$ They are also widely used to treat and prevent veterinary diseases in food-producing animals ${ }^{4}$. The precise and sensitive determination of the fluoroquinolone residue is now more than a necessity, because the widespread administration of these drugs can lead to the development of resistant human pathogens ${ }^{5}$. At present, the determination of EFX and CFX has been carried out for various types of samples such as $\operatorname{egg}^{6}$, chicken tissue ${ }^{7}$, honey and milk ${ }^{8}$. Given the complexity of some matrices, sample preparation alternatives such as solid phase extraction (SPE), magnetic solid phase extraction (MSPE) ${ }^{10}$, dispersive solid phase extraction $(\mathrm{DSPE})^{11}$ have been proposed. In this work, in order to achieve efficient extraction and using the minimum amount of solvent in the preconcentration stage, a new methodology will be proposed based on rotating disk sorptive extraction (RDSE). RDSE has been widely used for the determination of different pollutants ${ }^{12,13}$. The format of the device that includes a cavity in the disk provides high versatility for methodologies based on this method. This system allows the use of different extraction phases such as Octadecyl $\mathrm{C} 18^{14}$, ion exchange ${ }^{15}$, Oasis ${ }^{\circledR} \mathrm{HLB}^{16}$, among others. Oasis ${ }^{\circledR}$ HLB was selected in this study to carry out the extraction of the analytes by RDSE due it provides a hydrophilic-lipophilic balance, covering a wide polarity range of the analytes. After desorption the simultaneous determination of EFX and CFX was performed by derivative spectrofluorimetry. In the case of milk, the persistence of antibiotics has raised an issue of great concern in terms of public health, mainly because the consumption of dairy products is increasing. Presence of these residues cause in the long term, a probable bacterial resistance or inducing hypersensitivity to an antibiotic ${ }^{17,18}$. In this context, maximum residue limits (MRLs) have been established for a series of fluoroquinolones by the European Union, on the recommendation of its Committee for Veterinary Medicines ${ }^{19}$. The MRLs is $100 \mu \mathrm{g} \cdot \mathrm{L}^{-1}$ in milk for EFX and CFX. a)

b)<smiles>CC[NH+]1CCN(c2cc3c(cc2F)c(=O)c(C(=O)O)cn3C2CC2)CC1</smiles><smiles>O=C(O)c1cn(C2CC2)c2cc(N3CC[NH2+]CC3)c(F)cc2c1=O</smiles>

c)

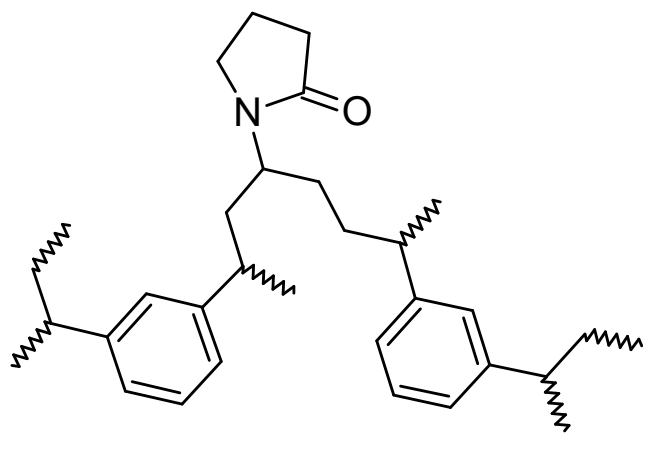

Figure 1: Structure of a) EFX, b) CFX y c) Oasis HLB. 


\section{EXPERIMENTAL}

\subsection{Reagents.}

Water from a Millipore Barnstead / Thermolyn deionizing water system was used. Enrofloxacin (99.8\% purity) and ciprofloxacin (99.0\% purity) were provided by Sigma-Aldrich (Milwaukee, WI, USA). A $1000 \mu \mathrm{g} \cdot \mathrm{mL}^{-1}$ analyte standard solution was prepared in methanol which was stable for at least 2 months at $-18^{\circ} \mathrm{C}$.

Intermediate standard solutions were prepared by dilution with methanol. Oasis HLB powder extraction sorbent (60 $\mu \mathrm{m}$ particle size) was obtained from cartridges provided by Waters (Milford, MA, USA). Octadecyl C18 provided by UCT (United Chemical Technologies, Bristol, England) was also evaluated as the absorption phase. All solvents were HPLC grade and were obtained from Merck (Darmstadt, Germany).

\subsection{Instruments and apparatus.}

A model KMC-1300V vortex mixer (Korea) and an ultrasonic bath, Branson ${ }^{\circledR}$ 2210 (China) were used to prepared solutions. Extraction was performed on magnetic stirrers, Stuart CB-162 (UK). A Hitachi F-2700 fluorescence spectrophotometer (Tokio, Japan) and $10 \mathrm{~mm}$ optical path quartz cells were used. The procedure for each measure was to correct the base line and then record the emission spectra in the $220-800 \mathrm{~nm}$ range, while at the same time processing the data using the FL solutions 4.1 for F-2700 software.

\subsection{Preparation of the rotating disks.}

The extraction device used in this study was a Teflon disk containing an embedded miniature magnetic stir bar. The disk has a cavity in one of its surfaces in which $50 \mathrm{mg}$ of Oasis ${ }^{\circledR}$ HLB sorbent was deposited. The cavity was covered with a glass fiber filter ( $3 \mu \mathrm{m}$ mean pore size) and sealed with a Teflon ring.

\subsection{Preparation of blank sample.}

For the validation of the method, a blank cow milk from the San José de los Lingues sector, San Fernando was used. These samples were collected in 1000 $\mathrm{mL}$ plastic bottles previously washed and dried. They were fortified with the analytes al different concentrations $\left(50-250 \mu \mathrm{g} \cdot \mathrm{L}^{-1)}\right.$ and kept refrigerated until use. Then the sample was centrifuged at $7.000 \mathrm{rpm}$ for 30 minutes after addition of $5 \mathrm{~mL}$ of $10 \%$ trichloroacetic acid. The supernatant was filtered through a cellulose filter $90 \mathrm{~mm}$. This was stored in an amber vial for later use. The blanks were processed under the same conditions in the absence of the analytes.

\subsection{Analytical Procedure.}

An aliquot of $5 \mathrm{~mL}$ of milk treated according to 2.4 was added in a $40 \mathrm{~mL}$ vial and then $20 \mathrm{~mL}$ of Mc Ilvaine-EDTA buffer $\left(\mathrm{pH} 4 ; 0.3 \mathrm{~mol} \cdot \mathrm{L}^{-1}\right)$ was added. The disk was immersed in the sample and extraction was performed at $2200 \mathrm{rpm}$ for 120 minutes. After extraction, the disk was placed in a $20 \mathrm{ml}$ vial containing 12.5 $\mathrm{mL}$ of methanol / Mc Ilvaine-EDTA buffer as a desorption mixture. The disk was stirred at $1600 \mathrm{rpm}$ for a desorption time of $15 \mathrm{~min}$. The final extract was measured by spectrofluorimetry at an excitation wavelength of $279 \mathrm{~nm}$. The blanks were carried out under the same conditions in the absence of the analyte.

\subsection{Optimization of variables.}

The optimization was carried out according to the procedure in 2.5. with 50 $\mathrm{mg}$ of sorbent phase for RDSE and a rotation velocity of $2200 \mathrm{rpm}$. The extraction time, buffer concentration and sample volume were optimized with blank samples enriched with $50 \mu \mathrm{g} \cdot \mathrm{L}^{-1}$ of EFX and CFX. The optimized method was then validated following the standard criteria established in Eurachem ${ }^{20}$ and the following analytical features were determined: linearity of standards, linearity of speaks, selectivity, limit of detection, limit of quantification, accuracy and precision.

\section{RESULTS AND DISCUSSION}

\subsection{Sorbent phase selection.}

Sorptive phases such as C18 and Oasis HLB have been considered in the determinations of these analytes using solid phase extraction (SPE), providing good analytical performance, consequently these same sorbents were tested in
RDSE for the extraction of both analytes. The extraction of CFX and EFX was carried out at a concentration of $50 \mu \mathrm{g} \cdot \mathrm{L}^{-1}$ using RDSE, where the recovery percentages were determined. As shown in Figure 2 the recoveries were considerably higher at $\mathrm{pH} 4$, achieving recovery percentages greater than $80 \%$ for the Oasis ${ }^{\circledR} H L B$ phase. In the same way, the spectral study of both phases was carried out in order to achieve the simultaneous determination of the analytes. Both sorbents provide a high retention of analytes in standard solutions. However, a higher variability was observed when $\mathrm{C} 18$ was used compared to Oasis HLB (Figure 2a).

In addition, the desorption process in $\mathrm{C} 18$, after the extraction of the milk blank sample, generated an emulsion on the glass fiber, which is attributed to the hydrophobic components of the milk and therefore their affinity with the phase. Due to this effect, the recovery percentages were reduced, as well as the spectral resolution decreased. Considering the above, Oasis ${ }^{\circledR} \mathrm{HLB}$ phase, that presents more than $80 \%$ recovery for the analytes under study (Figure 2a), was selected as the sorbent phase for the determination of EFX and CFX. Considering the above, the desorption process was optimized with the Oasis ${ }^{\circledR} H L B$ phase in the blank sample.

a)

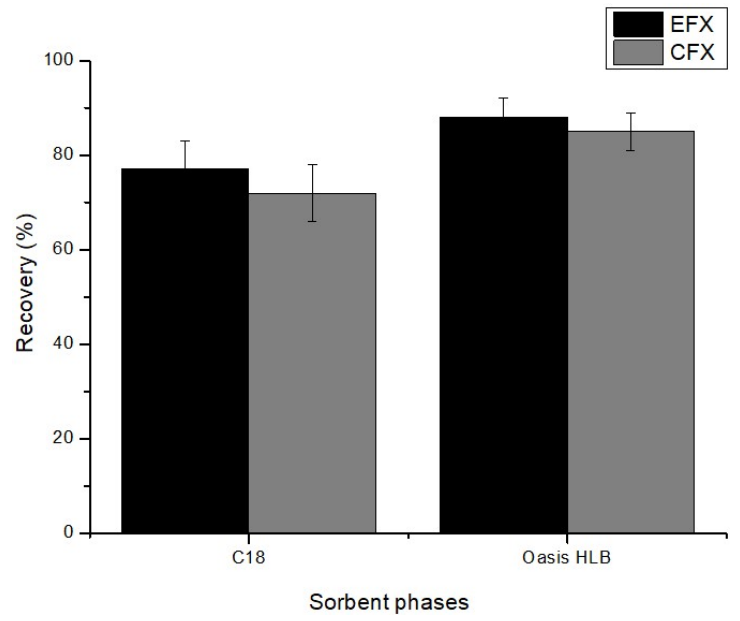

b)

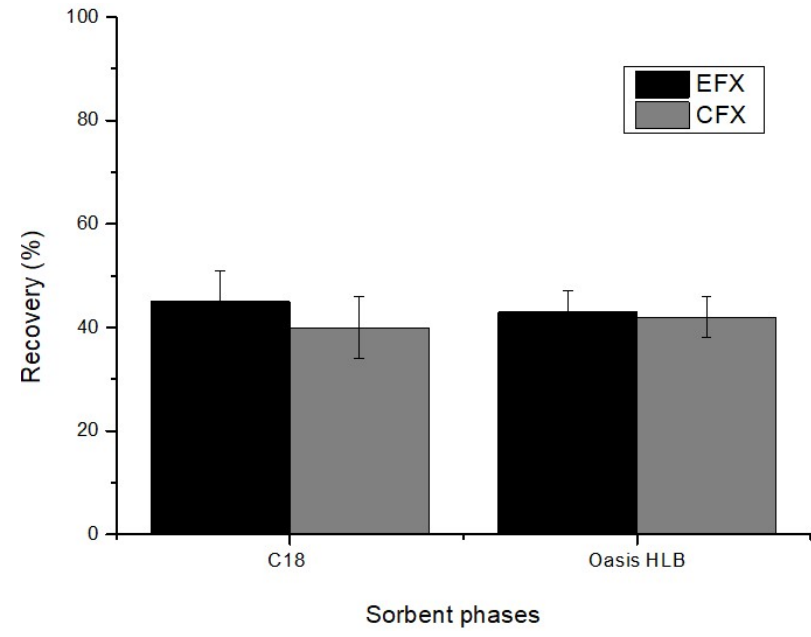

Figure 2. Recovery of the sorbent phases in the extraction for EFX and CFX at (a) $\mathrm{pH} 4$ and (b) $\mathrm{pH} 10$.

\subsection{Optimization of variables.}

The rotation speed of the disk was kept at the maximum speed reached by the magnetic stirrer, because under this condition the boundary layer formed on the surface of the sorption phase decreases and the mass transfer of analyte is faster ${ }^{21,12,13,21}$. Ultimately, the rotational speed of the disk was kept constant at $2200 \mathrm{rpm}$. The extraction time, buffer concentration and sample volume were optimized using milk samples enriched with a concentration of $50 \mu \mathrm{g} \cdot \mathrm{L}^{-1}$ of EFX and CFX. 
a)

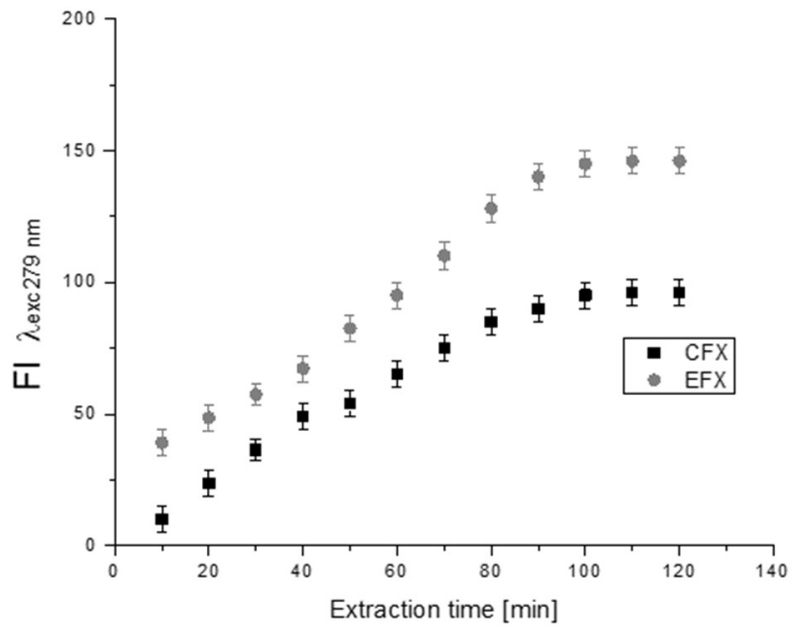

b)

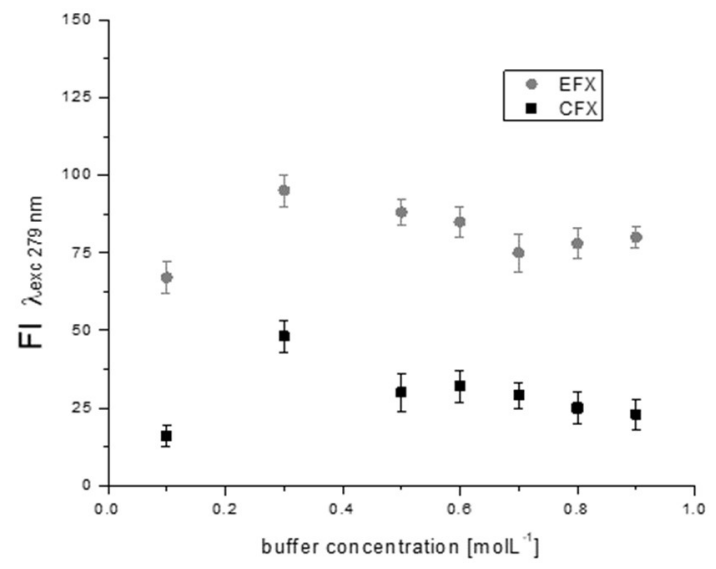

c)

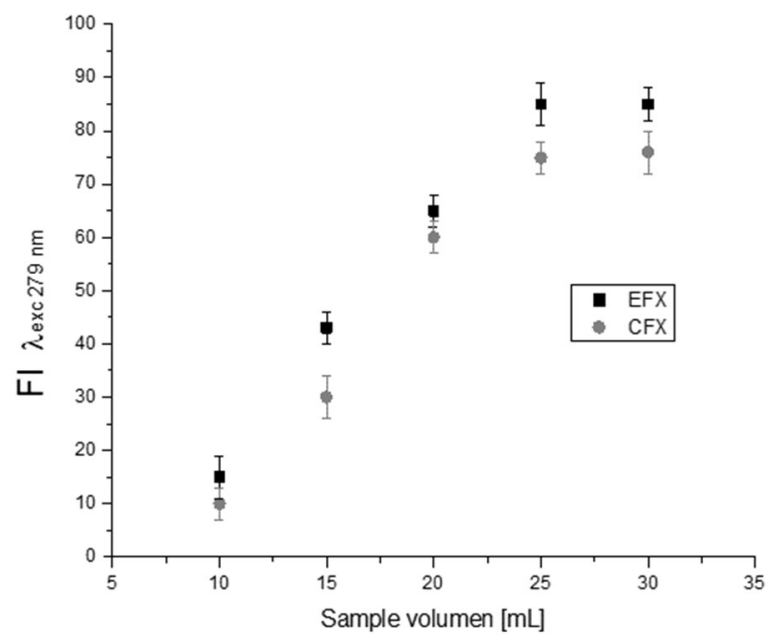

Figure 3. Effect of variables in the EFX and CFX extraction stage. a) extraction time, b) buffer concentration and c) sample volume.

As shown in Figure 3a, the extraction equilibrium was reached at $100 \mathrm{~min}$, achieving quantitative extractions. An extraction time of $120 \mathrm{~min}$ was selected as optimal. The Mc Ilvaine buffer with $2.5 \mathrm{~g}$ de EDTA was used in the extraction of EFX and CFX, which does not present any interfering signal at the wavelengths of analyte responses. The concentration of the Mc Ilvaine - EDTA buffer was studied between 0.1 and $0.9 \mathrm{M}$. EDTA, allows metal ions such as the calcium ion contained in the sample to be chelated, allowing this possible interference to be eliminated and thus favoring the extraction process. Figure $3 \mathrm{~b}$ shows that there is an increase in fluorescence intensity when the concentration of buffer increasing to $0.3 \mathrm{M}$. After this concentration of buffer, the formation of a precipitate appeared in the solution, which is reflected in the decrease in fluorescence intensity. A concentration of $0.3 \mathrm{M}$ was selected, being significant for the extraction process.
To study the effect of the sample volume, the extraction was studied between 10 and $30 \mathrm{~mL}$. Figure $3 \mathrm{c}$ shows a maximum response from $25 \mathrm{~mL}$, to favor the extraction and preconcentration of the analytes. A volume of $25 \mathrm{~mL}$ was selected as the sample volume.

Similarly, in the desorption stage, there are variables that are important to optimize. In the first instance, the study of the solvent to be used for the desorption was carried out. The results presented in Figure 4 show high recovery percentages for the analytes using methanol as desorption solvent. This solvent has an intermediate dielectric constant, compared to other solvents such as ethanol and acetonitrile, to which the behavior that favors desorption is attributed. In addition, a protic solvent that favors interactions between solvent and analyte. On the other hand, the spectral response was improved using methanol, given rise to more defined and more resolved signals, which facilitated the analyte measurements.

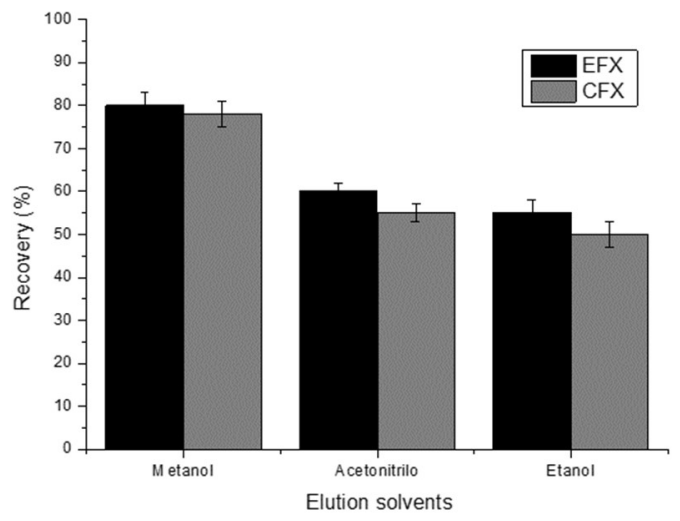

Figure 4. Solvents used for the desorption of EFX and CFX. Concentration 50 $\mu \mathrm{g} \cdot \mathrm{L}^{-1}$ and exc-em slit $10-10 \mathrm{~nm}$.

The study was continued with the optimization of the desorption time and the volume of methanol, as shown in Figure 5.

a)

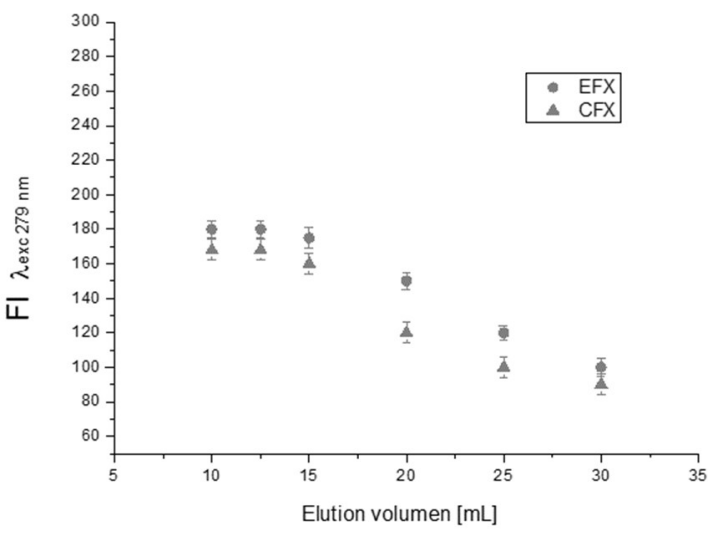

b)

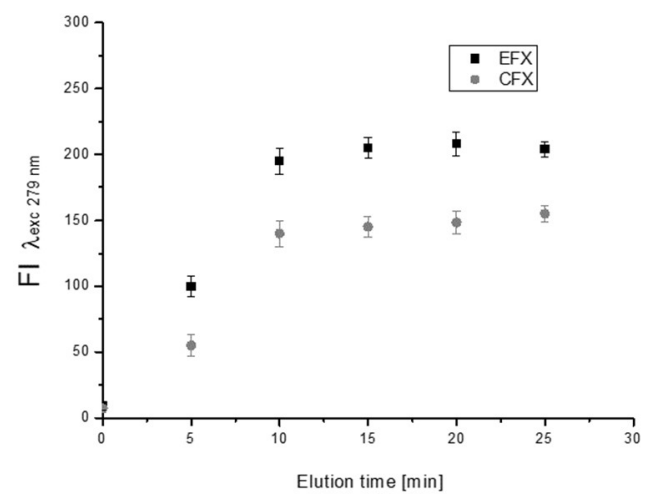

Figure 5. Effect of variables in the desorption step of EFX and CFX from the disk a) desorption volume and b) desorption time. 
Methanol volume was firstly studied varying between 10 and $40 \mathrm{~mL}$ using a desorption time of $15 \mathrm{~min}$. As shown in Figure 5a, volumes higher than $15 \mathrm{~mL}$ the fluorescence intensity decreased due to dilution of the desorbed analytes. A volume of $12.5 \mathrm{~mL}$ was selected, to favor preconcentration (concentration factor $=2$ ). It should be noted that in the desorption stage the stirring speed is a key factor, since when smaller volume of solvent is used, it is not convenient to use higher rotation velocities. This is to avoid the formation of a vortex that prevents contact of the sorptive phase with the desorption solvent. Therefore, the minimum volume of methanol corresponds to $10 \mathrm{~mL}$. This is due to the aforementioned and favoring the preconcentration factor, the desorption volume of $12.5 \mathrm{~mL}$ was selected. The desorption time was studied using $12.5 \mathrm{~mL}$ of methanol. Figure $5 \mathrm{~b}$ shows that the desorption equilibrium time is reached at 10 $\min$ for the analytes.

\subsection{Simultaneous determination of EFX and CFX.}

A range of excitation wavelengths was studied to find the optimum one that would allow the simultaneous determination of analytes. A value of $279 \mathrm{~nm}$ was selected to provide a difference to resolve the spectra and perform the determination. The EFX and CFX extracts were evaluated directly after desorption with RDSE subtracted from blank. Taking into account that the bands are considerably overlapped, derivative spectrofluorimetry was used, since it allows the resolution of the mixtures and the simultaneous determination of both antibiotics.

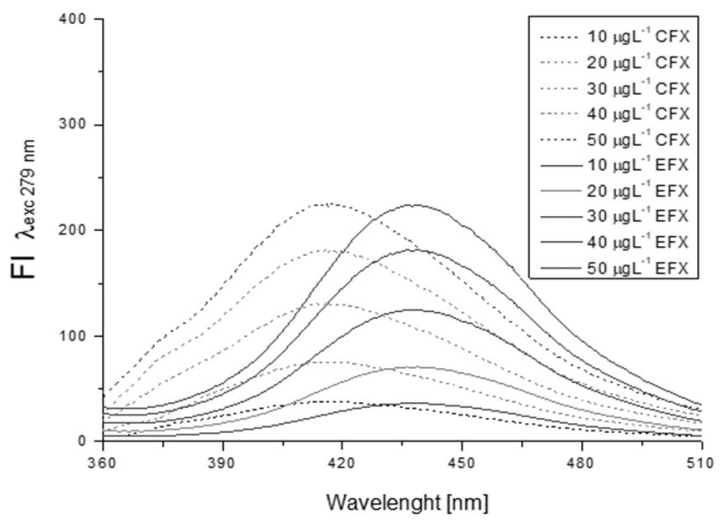

Figure 6: Zero-order fluorescence spectra of EFX and CFX at different concentrations.

Derivative spectrofluorimetry using the zero-crossing approach was used for the simultaneous determination, in which the spectral variables were studied. In this regard, the first and second derivatives are of greater analytical interest, because they disturb the sensitivity in a lower extent, since increasing the order of the derivative decreases the intensity of the signal, however, the spectral resolution obtained is higher ${ }^{22}$.

\subsection{Selection of spectral variables.}

The digital derivative spectra were based on the mathematical model of Savitzky Golay and were obtained using the software FL solutions coupled to the spectrofluorimeter. This method consists in the evaluation of the IF / $\Delta \lambda$ ratio corresponding to a fluorescence intensity column and a constant $\Delta \lambda$ scanning interval (expressed in $\mathrm{nm}$ ) using least squares resolution for differentiation, which favors the reduction of background noise ${ }^{23}$. When this method is used, different spectral variables must be optimized. To select the derived order, the maximum resolution and sensitivity must be considered without sacrificing the signal-to-noise ratio. Figure 7 a shows that first derivatives allowed determining EFX and CFX by the zero-crossing approach. The smoothing factor is the number of points used for differentiation, which is directly dependent on the wavelength range used. As this factor increases, the heights of the derivatives decrease and a clear reduction in noise is also observed. In addition, the amplification factor increased the analytical signal and the background noise in the same proportion. This factor only affects the achievement of a good reading of the analytical signal since it does not increase the sensitivity. It is necessary to achieve a compromise between the amplification of the signal and the distortion effect in the spectral bands, because if the signal is amplified excessively, the spectrum can become distorted and cause an erroneous reading. a)

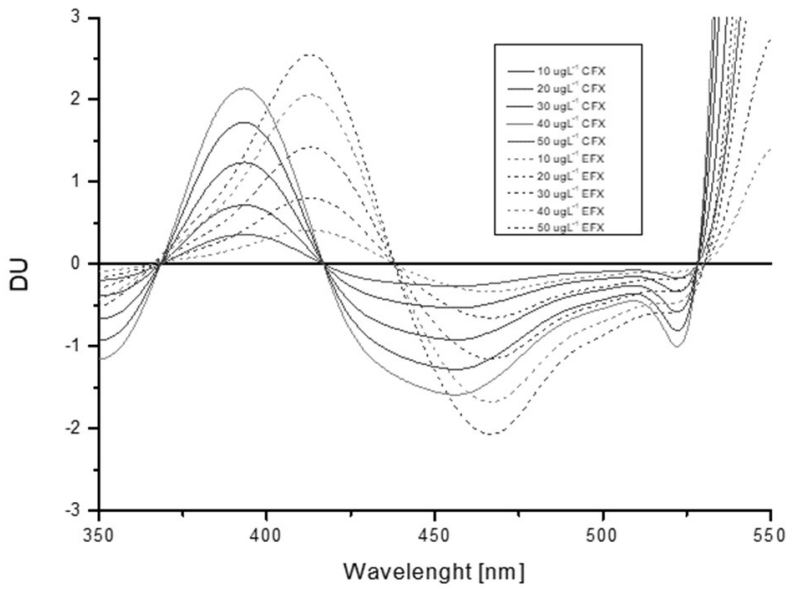

b)

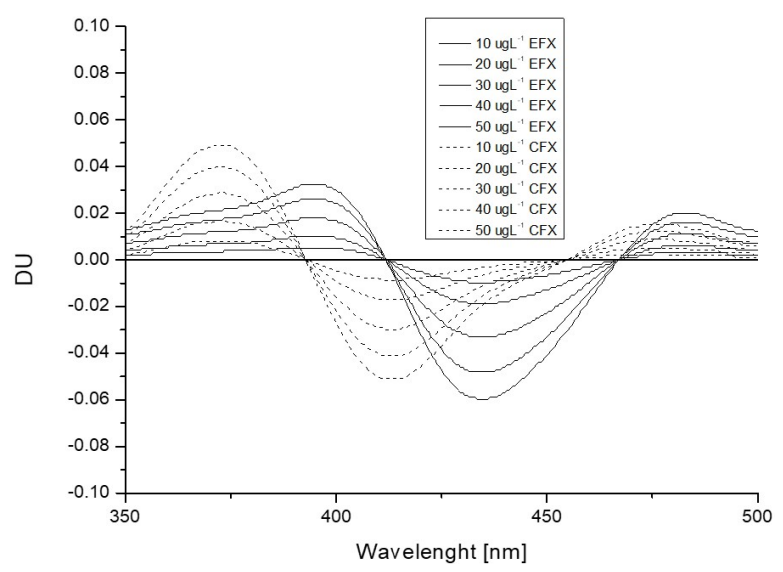

Figure 7: Derivative spectra of EFX and CFX obtained at different concentrations in methanol. (a) First derivative, (b) Second derivative.

\subsection{Analytical wavelength selection.}

As can be seen in Figure 7a, the first-order derivatives present characteristic areas to quantify CFX and EFX. Furthermore, a good linearity of the signals with the analyte concentration was observed. The determination was performed using the zero-crossing approach in the first derivative. The wavelengths which can be used for the simultaneous determination by zero-crossing were $417 \mathrm{~nm}$ for EFX and $438 \mathrm{~nm}$ for CFX, because they provided more sensitivity and a lower background noise. The increment in the order of the derivative was discarded because it resulted in an increase in noise and a decrease in sensitivity. The smoothing factor was 95 points and an amplification factor of 100 was selected, both options provided by the software FL Solutions.

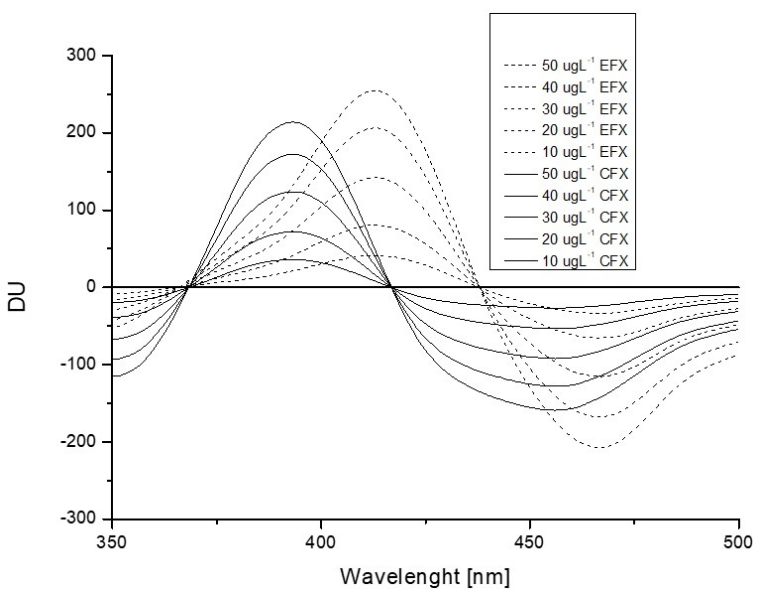

Figure 8. First-derivative spectrum for EFX and CFX in methanol at different analyte concentrations. 


\subsection{Analytical features of the method.}

The calibration curves were obtained by measuring the first derivative values (DU) for EFX, $(\lambda=417 \mathrm{~nm})$ and CFX $(\lambda=438 \mathrm{~nm})$, against the concentrations of the respective analytes. The linear regression equations were obtained (Table 1). The limit of detection (LOD) and the limit of quantification (LOQ) were calculated by using the $3.3 \sigma / \mathrm{S}$ and $10 \sigma / \mathrm{S}$ criteria, respectively, where $\mathrm{S}$ is the slope of the calibration curve and $\sigma$ the standard deviation corresponding to the response of 11 blanks. The determination range was defined between LOQ and the limit of linearity. In this context, when the proposed method was applied it was possible to obtain an acceptable degree of linearity with accurate and precise results. The analytical features of the method are shown in Table 1.

Table 1: Analytical features of the method.

\begin{tabular}{|c|c|c|c|c|c|c|}
\hline Analyte & $\begin{array}{c}\text { Analytical } \\
\text { Wavelenght } \\
{[\mathrm{nm}]}\end{array}$ & $\begin{array}{c}\text { Linearity } \\
\text { (spiked } \\
\text { samples) } \\
\left(\mu \mathrm{g} \cdot \mathbf{L}^{-1}\right)\end{array}$ & $\underset{\left(\boldsymbol{\mu g} \cdot \mathbf{L}^{-1}\right)}{\mathbf{L O D}}$ & $\begin{array}{c}\mathbf{L O Q} \\
\left(\mu \mathrm{g} \cdot \mathbf{L}^{-1}\right)\end{array}$ & $\begin{array}{c}\operatorname{Re} \\
\pm \mathrm{RSD} \\
(\%) \\
10 \mu \mathrm{g} \cdot \mathrm{L}^{-} \\
\frac{1}{0}\end{array}$ & $\begin{array}{l}\operatorname{Re} \pm \text { RSD } \\
(\%) \\
50 \mu \mathrm{g} \cdot \mathrm{L}^{-1}\end{array}$ \\
\hline Enrofloxacin & 417 & $\begin{array}{r}\mathrm{DU}=4.88 \\
{[\mathrm{EFX}]-2.85} \\
\mathrm{R}^{2}=0.9937\end{array}$ & 2.98 & 9.04 & $\begin{array}{c}98.80 \pm \\
3.8\end{array}$ & $\begin{array}{c}99.78 \pm \\
3.5\end{array}$ \\
\hline Ciprofloxacin & 438 & $\begin{array}{c}\mathrm{DU}=5.81 \\
{[\mathrm{CFX}]-3.23} \\
\mathrm{R}^{2}=0.9941\end{array}$ & 2.56 & 7.75 & $\begin{array}{c}100.5 \pm \\
3.3\end{array}$ & $\begin{array}{c}100.3 \pm \\
2.6\end{array}$ \\
\hline
\end{tabular}

Table 2: Application of the RDSE method to spiked samples.

\begin{tabular}{|c|c|c|c|}
\hline \multirow{2}{*}{ Analytes } & \multirow{2}{*}{$\begin{array}{c}\text { Spiked level } \\
\left(\boldsymbol{\mu g} \cdot \mathbf{L}^{-1}\right)\end{array}$} & \multicolumn{2}{|c|}{ Measured levels $\left(\boldsymbol{\mu g} \cdot \mathbf{L}^{-\mathbf{1}}\right)$} \\
\cline { 3 - 4 } & 10 & Milk A & Milk B \\
\hline \multirow{2}{*}{ Enrofloxacin } & 30 & $30.91 \pm 1.3$ & $10.01 \pm 1.2$ \\
\cline { 2 - 4 } & 10 & $10 . \pm 1.5$ & $29.92 \pm 1.5$ \\
\hline \multirow{2}{*}{ Ciprofloxacin } & 30 & $29.96 \pm 1.7$ & $9.92 \pm 1.7$ \\
\cline { 2 - 4 } & & \multicolumn{2}{|c|}{. }
\end{tabular}

The analytical features were obtained under the extraction conditions using the optimized RDSE method. The proposed method was evaluated by characterizing its analytical performance in terms of linearity, precision, recovery, limit of detection (LOD) and limit of quantification (LOQ). The calibration graphs of the analytes were prepared at five concentration levels and it were linear in the range of 9.04-86.4 $\mu \mathrm{g} \cdot \mathrm{L}^{-1}$ for EFX and in the range of 7.75-83.2 $\mu \mathrm{g} \cdot \mathrm{L}^{-1}$ for CFX, with correlation coefficients (r) of 0.9937 and 0.9941 , respectively. The recovery $(\mathrm{Re})$ and precision values were also obtained under the optimal conditions determined. It was observed that the optimized extraction process was highly efficient, with good recoveries ranging from $98.80 \%$ to $100.5 \%$ for the two concentration levels (Table 1). Real samples were examined to validate the applicability of the developed RDSE method and to evaluate the effects of the matrix for the extraction of fluoroquinolones.

Table 2 showed the concentration and recovery in commercial milk samples for both analytes studied. The analytes were not detected in the samples.

The new proposed method does not require organic solvents for quantitative extractions and, consequently, does not generate toxic residues. The new developed method is rated an excellent green level, according to the proposed eco-scale proposed by Galuszka et $\mathrm{al}^{24}$. Finally, the proposed method was compared with those reported for fluoroquinolones in milk samples (Table 3) showing several improvements such as rapidity, lower sample volume, low cost and easy operation. The latter, particularly in the simplicity and automation of the extraction process compared to SPE and DLLME. Furthermore, the non-use of organic solvents in the deproteinization stage makes the method environmentally friendly.

Re: recovery.

Table 3. Comparison of the proposed RDSE method with other sample preparation.

\begin{tabular}{|c|c|c|c|c|c|c|c|c|c|}
\hline Method & Analytes & Technique & Solvents used in extraction/desorption & $\begin{array}{r}\text { Sample } \\
\text { volume } \\
(\mathrm{mL})\end{array}$ & $\begin{array}{l}\text { Analytical } \\
\text { Eco Scale } \\
\text { total score }\end{array}$ & $\begin{array}{c}\text { LOD } \\
\underset{(\mu g}{\mu} \\
\left.\mathbf{L}^{-1}\right)\end{array}$ & $\begin{array}{c}\text { Recovery } \\
(\%)\end{array}$ & $\begin{array}{r}\text { RSD } \\
(\%)\end{array}$ & Ref. \\
\hline SPE- C18 & $\begin{array}{l}\text { Enrofloxacin } \\
\text { Ciprofloxacin }\end{array}$ & HPLC-FD & TFA/ACN/MEOH & 5 & 69 & $\begin{array}{l}2.02- \\
2.28\end{array}$ & $95.9-99.7$ & $\begin{array}{c}0.03- \\
0.94\end{array}$ & 14 \\
\hline $\begin{array}{l}\text { SPE- } \\
\text { Oasis } \\
\text { HLB }\end{array}$ & Antibiotics & LC-HRMS & $\begin{array}{l}\text { MCILVAINE BUFFER / HEXANE } \\
\text { /METHANOL }\end{array}$ & 5 & 74 & oct- 15 & $88-99$ & $<20$ & 25 \\
\hline $\begin{array}{c}\text { SO- } \\
\text { DLLME- } \\
\text { DES-BE }\end{array}$ & $\begin{array}{l}\text { Sparfloxacin } \\
\text { Gatifloxacin } \\
\text { Enrofloxacin } \\
\text { Ciprofloxacin } \\
\text { Lomefloxacin } \\
\text { Levofloxacin }\end{array}$ & MECC-UV & $\begin{array}{c}\text { N-DECANOIC ACID/METHYLTRIOCTYL } \\
\text { AMMONIUM } \\
\text { BROMIDE }\end{array}$ & 150 & 84 & 06-oct & $\begin{array}{l}87.8- \\
114.1\end{array}$ & $<7.6$ & 8 \\
\hline $\begin{array}{l}\text { MPFS- } \\
\text { DID }\end{array}$ & $\begin{array}{l}\text { Fleroxacin } \\
\text { Lomefloxacin } \\
\text { Norfloxacin } \\
\text { Ofloxacin }\end{array}$ & HPLC-UV & $\mathrm{ETOH} / \mathrm{HCl} / \mathrm{HEXANO} / \mathrm{ACN} / \mathrm{NH}_{4} \mathrm{OH} / \mathrm{MEOH}$ & 0.5 & 80 & 30 & $70-75$ & $\begin{array}{l}05- \\
\text { ago }\end{array}$ & 26 \\
\hline $\begin{array}{l}\text { RDSE- } \\
\text { Oasis } \\
\text { HLB }\end{array}$ & $\begin{array}{l}\text { Enrofloxacin } \\
\text { Ciprofloxacin }\end{array}$ & $\begin{array}{l}\text { SPECTRO } \\
\text { FLUORIMETRY }\end{array}$ & MCILVAINE BUFFER/METHANOL & 5 & 76 & $\begin{array}{l}2.06- \\
3.34\end{array}$ & $\begin{array}{l}98.8- \\
100.3\end{array}$ & $\begin{array}{c}2.6- \\
3.8\end{array}$ & $\begin{array}{l}\text { This } \\
\text { work }\end{array}$ \\
\hline
\end{tabular}




\section{CONCLUSIONS}

A green method using first order derived spectrofluorimetry, accurate, simple and inexpensive has been developed for the simultaneous determination of EFX and CFX in milk samples. The successful recovery for each analyte in the blank samples corroborates that there was no matrix effect. The evaluation of the target analytes showed good linearity, satisfactory recovery, limit of detection and precision. The results obtained indicated that the developed method is an excellent alternative for the analysis of these fluoroquinolones in milk samples. The contribution of this work is the development of a strategy for simultaneous determination and can be considered as a good analytical proposal. It should be noted that the results meet the analytical quality criteria and advance towards the development of green chemistry ${ }^{24}$.

\section{AKNOLWLEDGEMENTS}

The authors thank FONDECYT projects No. 1140716 and No. 1180742 and CONICYT grant 21140655 for financing this research.

\section{REFERENCES}

1. FAO Food Nutr Pap, 41, 1-166, (1996).

2. V. F. Samanidou, E. A. Christodoulou and I. N. Papadoyannis, J. Sep. Sci., 28, 325-331, (2005).

3. F. Cañada-Cañada, A. Espinosa-Mansilla and A. M. de la Peña, J. Sep. Sci., 30, 1242-1249, (2007).

4. M. Lolo, S. Pedreira, C. Fente, B. I. Vázquez, C. M. Franco and A. Cepeda, J. Agric. Food Chem., 53, 2849-2852, (2005).

5. E. M. Agency, 44, 0-18, (2014).

6. M. Gbyłik-Sikorska, A. Posyniak, A. Gajda and T. Bładek, Bull. Vet. Inst. Pulawy, 57, 351-355,(2013).

7. N. R. Moghadam, S. R. Arefhosseini, A. Javadi, F. Lotfipur, M. Ansarin, E. Tamizi and M. Nemati, Iran. J. Pharm. Res., 17, 1182-1190, (2018).

8. K. Yu, M. E. Yue, J. Xu and T. F. Jiang, Food Chem., 332, 127371,(2020).

9. X. Wang, W. Zhou, C. Wang and Z. Chen, Talanta, 186, 545-553, (2018).

10. A. Wen, G. Li, D. Wu, Y. Yu, Y. Yang, N. Hu, H. Wang, J. Chen and Y. Wu, J. Chromatogr. A, 1612, (2020)

11. K. Hu, Y. Shi, W. Zhu, J. Cai, W. Zhao, H. Zeng, Z. Zhang and S. Zhang, Food Chem., 128079, (2020).

12. C. M. S. Vieira, G. Mafra, R. Brognoli, P. Richter, M. Rosero-Moreano and E. Carasek, Talanta, 208, 120459, (2019).

13. V. Manzo, J. Goya-Pacheco, D. Arismendi, M. Becerra-Herrera, A. CastilloAguirre, R. Castillo-Felices, M. Rosero-Moreano, E. Carasek and P. Richter, Anal. Chim. Acta, 1087, 1-10, (2019).

14. M. Y. Piñero, M. Fuenmayor, L. Arce, R. Bauza and M. Valcárcel, Microchem. J., 110, 533-537, (2013).

15. X. Liang, P. Hu, H. Zhang and W. Tan, J. Pharm. Biomed. Anal., 166, 379$386,(2019)$.

16. A. Junza, J. Saurina, D. Barrón and C. Minguillón, J. Chromatogr. A, 1460, 92-99, (2016).

17. H. Sumano López and L. Ocampo Camberos, in Farmacología Veterinaria, Mc Graw Hill, Mexico D.F., 3th edn., p. 305, (2006).

18. H. Sumano López and L. Ocampo Camberos, in Farmacología Veterinaria, Mc Graw Hill, Mexico D.F., 3th edn., pp. 45-105, (2006).

19. R. Companyó, M. Granados, J. Guiteras and M. D. Prat, Anal. Bioanal. Chem., 395, 877-891, (2009).

20. B. Magnusson and U. Örnemark, Eurachem Guid., 1-70, (2014).

21. A. Giordano, P. Richter and I. Ahumada, Talanta, 85, 2425-2429, (2011).

22. E. I. El-Kimary and M. A. A. Ragab, Spectrochim. Acta - Part A Mol. Biomol. Spectrosc., 204, 677-684, (2018).

23. S. Abraham and Golay Marcel J.E, 36, 1627-1639, (1964).

24. A. Gałuszka, P. Konieczka and Z. M. Migaszewski, 37, 61-72, (2012).

25. L. M. Chiesa, L. DeCastelli, M. Nobile, F. Martucci, G. Mosconi, M. Fontana, M. Castrica, F. Arioli and S. Panseri, Lwt, 131, 109783, (2020).

26. C. Vakh, A. Pochivalov, S. Koronkiewicz, S. Kalinowski, V. Postnov and A. Bulatov, Food Chem., 270, 10-16, (2019). 